\title{
The Heterogeneity Research of the Impact of EPU on Environmental Pollution: Empirical Evidence Based on 15 Countries
}

\author{
Ying Chen * ${ }^{\mathbb{O}}$, Xiaoqian Shen and Li Wang
}

check for updates

Citation: Chen, Y.; Shen, X.; Wang, L. The Heterogeneity Research of the Impact of EPU on Environmental Pollution: Empirical Evidence Based on 15 Countries. Sustainability 2021, 13, 4166. https://doi.org/10.3390/ su13084166

Academic Editor: Adriana Del Borghi

Received: 19 March 2021

Accepted: 7 April 2021

Published: 8 April 2021

Publisher's Note: MDPI stays neutral with regard to jurisdictional claims in published maps and institutional affiliations.

Copyright: (C) 2021 by the authors Licensee MDPI, Basel, Switzerland. This article is an open access article distributed under the terms and conditions of the Creative Commons Attribution (CC BY) license (https:/ / creativecommons.org/licenses/by/ $4.0 /)$.
School of Economics, Fudan University, Shanghai 200433, China; xqshen18@fudan.edu.cn (X.S.); wangli18@fudan.edu.cn (L.W.)

* Correspondence: chenying18@fudan.edu.cn

\begin{abstract}
While economic growth has been the main goal of countries around the world, environmental problems such as air pollution have also arisen. Since the increase in economic uncertainty is limiting production capacity and consumers' marginal propensity to consume, which reduces $\mathrm{CO}_{2}$ emissions, economic policy uncertainty has become one of the most important factors affecting $\mathrm{CO}_{2}$ emissions. COVID-19 has demonstrated that economic policy uncertainty reduces the enthusiasm of market participants, which, in turn, reduces energy demand and $\mathrm{CO}_{2}$ emissions. In order to further study the impact of economic policy uncertainty on air pollution, this study uses a panel model to empirically test the data for a sample of 15 countries covering the period from 1997 to 2019. According to the empirical results, we find that the economic policy uncertainty has a significant negative impact on per capita $\mathrm{CO}_{2}$ emissions. That is, the higher the uncertainty of economic policy, the lower the per capita $\mathrm{CO}_{2}$ emissions of countries. What's more, this negative effect is larger in emerging market countries than in advanced countries.
\end{abstract}

Keywords: economic policy uncertainty; air pollution; investment effect; consumption effect

\section{Introduction}

Pollution has become one of the serious problems that need to be solved urgently in the world. Pollution is not only a serious threat to human health but also has a significant impact on the national economy (Chang et al. [1]). Since the 1990s, China, India, and other emerging market countries have experienced rapid economic growth. At the same time, pollution has become an important problem to these countries (Zheng and Kahn [2]). However, the enterprise is one of the main bodies of pollution control, whose cost and benefit of environmental protection have great uncertainty (Dietz and Fankhauser [3]). The uncertainty of macroeconomic policy will make enterprises reduce investment (Bloom [4]). The fluctuation of investment and output will have an impact on pollution (Acaravci and Ozturk [5] and Soytas and Sari [6]). When making investment decisions, enterprises need to weigh the benefits of waiting for more available information and the return on their investment, and then decide the optimal time to invest. Uncertain events will temporarily increase the return of waiting for information, thus forming an investment cycle (Bernanke [7], Pindyck [8], Dixit [9]). For example, during COVID-19, many companies experienced shutdowns and production reductions due to the epidemic's lockdowns of domestic and international economic activities, which in part led to lower energy use and $\mathrm{CO}_{2}$ emissions.

Recently, some literatures make researches on the relationship between economic policy uncertainty and pollution and obtain different conclusions. For example, Adedoyin and Zakari [10] propose that increase in the economic policy uncertainty leads to decrease in $\mathrm{CO}_{2}$ emissions in the short run, but will increase $\mathrm{CO}_{2}$ emissions in the long run. However, Adams et al. [11] hold the view that increase in the economic policy uncertainty leads to the 
rise of carbon emissions both in the short and long run. However, they do not pay much attention on the transmission mechanism from economic policy uncertainty to pollution and do not take into account whether there exists heterogeneity between different groups of countries.

Figure 1 presents the synergistic relationship between $\mathrm{CO}_{2}$ emissions and economic policy uncertainty of the world's top four economies. They are the United States, China, Japan, and Germany, respectively. From Figure 1, we can find that the $\mathrm{CO}_{2}$ emissions of China fluctuate greatly, while the fluctuations of the United States, Japan, and Germany are similar. At the same time, the $\mathrm{CO}_{2}$ emissions and economic policy uncertainty of all these four countries show a significant negative synergistic relationship. When economic policy uncertainty rises across countries, it is accompanied by a decline in $\mathrm{CO}_{2}$ emissions. Conversely, when economic policy uncertainty decreases across countries, it is accompanied by an increase in $\mathrm{CO}_{2}$ emissions.
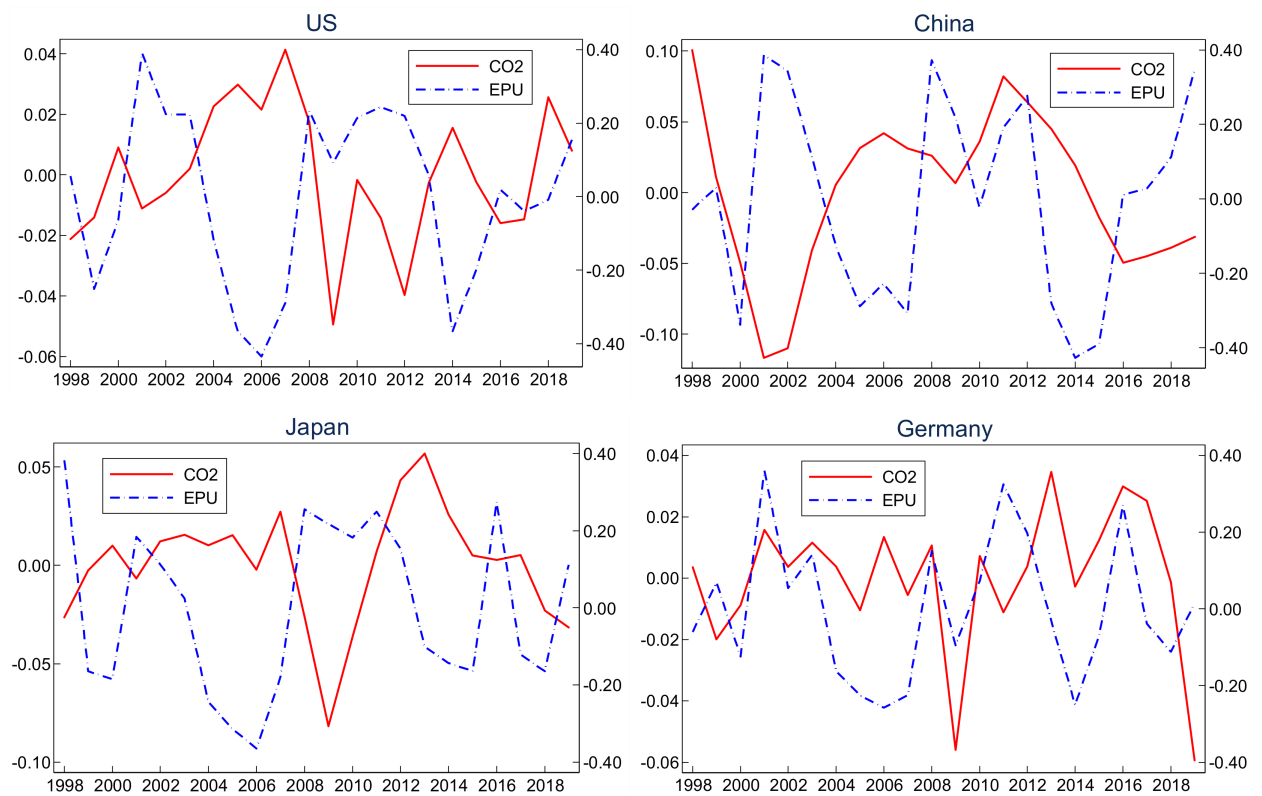

Figure 1. The co-movement fact between $\mathrm{CO}_{2}$ and economic policy uncertainty index (EPU)

Notes: (1) The data sample covers the period 1998Q1 to 2019Q4, the source of $\mathrm{CO}_{2}$ is the World Bank, and the data of EPU (economic policy uncertainty) is from https: / / www.policyuncertainty.com/ (accessed on 1 March 2021). (2) $\mathrm{CO}_{2}$ emissions and EPU of the United States, China, Japan, and Germany are all the fluctuation values after HP Filtered $(\lambda=100)$. (3) $\mathrm{CO}_{2}$ emissions of the four countries adopt the logarithm of per capita $\mathrm{CO}_{2}$ emissions, and the EPU of the four countries adopt the logarithm of the EPU index. (4) In the figure, the red solid line is calibrated with the ordinate left axis, and the blue dotted line is calibrated with the ordinate right axis.

Based on the reverse synergetic relationship between $\mathrm{CO}_{2}$ emissions and economic policy uncertainty of the four countries and the heterogeneity of fluctuation of $\mathrm{CO}_{2}$ emissions between China and the other three advanced countries, we focus on the transmission mechanism from economic policy uncertainty to $\mathrm{CO}_{2}$ emissions, as well as the heterogeneity between emerging market countries and advanced countries, trying to make up for the deficiency of existing literatures.

This study uses an empirical model to further analyze the panel data of 15 countries covering the period from 1997 to 2019. According to the empirical results, we find that (1) economic policy uncertainty has a significant negative impact on per capita $\mathrm{CO}_{2}$ emissions, that is, the higher the economic policy uncertainty is, the lower the per capita $\mathrm{CO}_{2}$ emissions are. (2) The negative impact of emerging market countries is significantly larger 
than that of advanced countries, which shows that the "consumption effect" of emerging market countries' economic policy uncertainty is far larger than the "investment effect."

The existing representative literature on social driving factors on environmental pollution can be divided into three main strands. One strand focuses on the causal effect among economic growth, energy consumption, and pollution emission. EKC hypothesis (Environmental Kuznets Curve) holds that economic growth will be accompanied by environmental deterioration. When the economy reaches a certain threshold, economic growth will be accompanied by environmental improvement (pollution reduction), thus forming an inverted U-shaped curve between environmental pollution and economic growth (Barassi and Spagnolo [12]). For example, Grossman and Krueger [13] hold the view that for most indicators, economic growth initially leads to environmental degradation, and then enters the improvement stage. The turning points of different pollutants are different, but in most cases, these turning points appear before the country's per capita income reached $\$ 8000$.

Acaravci and Ozturk [5] find that there exists a positive correlation between economic growth and $\mathrm{CO}_{2}$ emissions in Denmark, Germany, Greece, Italy, and Portugal. In addition, Soytas and Sari [6] point out that there is a long-term and short-term positive correlation between economic growth and $\mathrm{CO}_{2}$ emissions. Ang [14], Zhang and Cheng [15], and lean and Smyth [16] further propose a unidirectional causality running from economic growth to energy consumption, and pollution emissions mainly come from energy consumption that promotes economic growth (Cai et al. [17]). At the same time, some literatures report bidirectional causality between energy consumption and economic growth. Economic growth is not only the cause of energy consumption, but also the result of energy consumption (Belloumi [18], Fallahi [19]).

The second strand analyzes the relationship among tax policy uncertainty, emission reduction policy uncertainty and pollution. Farzin and Kort [20] believe that the higher the pollution tax rate, the more pollution likely to be generated. By comparing the impact of uncertainty of tax revenue scale and time to pay taxes on the investment of pollution reduction, they find that uncertainty of tax revenue scale has a larger impact on the investment of pollution reduction. Pearce [21] and Jotzo et al. [22] believe that the great cost of policy uncertainty affects the scale of emission reduction and pollution control. Teeter and Sandberg [23] find that enterprises can develop innovative ability to deal with policy supervision, policy changes will cause changes in enterprises' coping ability, and policy uncertainty will affect how the enterprises react.

The third strand studies the relationship between economic policy uncertainty and pollution. Wang et al. [24] find that there is a positive relationship between $\mathrm{CO}_{2}$ emissions and the world uncertainty index in the long run, and Jiang et al. [25] find out that high economic policy uncertainty leads to the rise of carbon emissions in the United States. Adams et al. [11] use WUI index to do empirical test with data from 10 countries, and find out that increase in economic policy uncertainty leads to an increase in $0.002 \%$ of $\mathrm{CO}_{2}$ emissions in the short term and $0.011-0.012 \%$ in the long term. At the same time, they point out that there exists bidirectional causal effect between economic policy uncertainty and $\mathrm{CO}_{2}$ emission. Adedoyin and Zakari [10] adopt the data from the United Kingdom to make empirical test, and find that high economic policy uncertainty causes the decline of $\mathrm{CO}_{2}$ in the short run, but the rise of $\mathrm{CO}_{2}$ in the long run, and Granger causality test shows that there is only a unidirectional causality from economic policy uncertainty to $\mathrm{CO}_{2}$.

Some literatures believe that oil price fluctuation is the main cause of economic or financial policy uncertainty. Rehman [26] finds that the economic policy uncertainty is associated with global oil price shocks in India, Spain, and Japan based on empirical tests. Degiannakis et al. [27] hold the view that unexpected changes in oil prices can cause significant fluctuations in a company's future cash flow, leading to increased uncertainty of the company's stock price. Antonakakis et al. [28] report bidirectional causal relationship between economic policy uncertainty and oil prices. Higher oil prices will have a negative impact on the economy, forcing the authorities to adopt policies to alleviate the downward 
pressure caused by oil price shocks. Due to the variation of policy uncertainty caused by oil price fluctuations, it exists a negative impact on the investment and output decisions of firms, which in turn puts downward pressure on oil prices. Therefore, Bekiros et al. [29] think that the information of economic policy uncertainty plays an important role in the changes in oil prices.

The impact of changes in the supply and demand not only produces energy price fluctuations, but also leads to negative expectations for the macroeconomic development. It would make the economic policy uncertainty form close coupling relationship with energy consumption and then affect pollution. Economic policy uncertainty leads to higher energy consumption and thus has a negative impact on environmental quality (Danish et al. [30]). Pirgaip and Dinçergök [31] use the economic policy uncertainty index (EPU) to study the casual effect among the economic policy uncertainty, energy consumption, and $\mathrm{CO}_{2}$ emissions in G7 countries and find that Japan's economic policy uncertainty would increase energy consumption, and the economic policy uncertainty of the United States and Germany increases $\mathrm{CO}_{2}$ emissions of both countries.

Some other literatures propose that the economic policy uncertainty is associated with stock price fluctuations. For example, Brogaard et al. [32] propose that one additional EPU is accompanied by a 1.5\% (annualized 6.1\%) increase in forecasted 3-month abnormal returns. Baker et al. [33] also hold the view that economic policy uncertainty is accompanied with stock price volatility, and adopt micro data of enterprises to do test, the results show that increase in the economic policy uncertainty will leads to the reduction in investment, especially in the industries with strong policy sensitivity such as infrastructure construction. Based on the existing research, there are two main paths about how the economic policy uncertainty index affects carbon emissions, namely, the investment effect and consumption effect (Wang et al. [24]). One of the key factors of controlling environmental pollution and green industry transformation is that enterprises adopt more efficient pollution control equipment and technologies. Policy uncertainty will inhibit enterprises' investment in those equipment and technologies (Farzin and Kort [20]). One path is that the increase in economic policy uncertainty will reduce the investment on green energy and renewable energy, which reduces the substitutability of traditional energy and increases carbon emissions. Therefore, this path is called the investment effect. For example, Adams et al. [11] and Teeter and Sandberg [23] propose that enterprises will choose to cut costs and adopt a wait-and-see policy to avoid economic losses, thus hindering the upgrading and development of green capacity.

Consumption effect is opposite to the investment effect. The increase in economic policy uncertainty leads to the decreases of socioeconomic dynamism, production, and residents' consumption. A s a result, lower per capita $\mathrm{CO}_{2}$ would be generated. This mechanism is named "consumption effect." Coibion et al. [34] make a survey covering nearly 10,000 households in the six largest euro area countries (Belgium, Germany, France, Italy, the Netherlands, and Spain) in 2020, the empirical test shows that the increase in economic policy uncertainty leads to the decline of household expenditure and enterprise investment. Gulen and Ion [35] and Stockhammar and Österholm [36] hold the view that there is a significant negative correlation between corporate investment and policy uncertainty. Aizenman and Marion [37] point out that from 1970 to 1985, the policy uncertainty of 46 emerging market countries is negatively correlated with investment and growth. Gulen and Ion [35] prove that the negative relationship between investment and policy uncertainty is stronger for enterprises with higher degree of irreversibility of investment and enterprises with higher degree of dependence on government expenditure. Bloom et al. [38] propose that increase in economic policy uncertainty leads to the decline of GDP.

In the existing literature, studies on the impact of economic policy uncertainty on environmental pollution mainly focus on the empirical test and then obtain the conclusion about one or several countries. Most of them use EPU, WUI, or some other economic indices to represent uncertainty, and use $\mathrm{CO}_{2}$ emissions, $\mathrm{PM}_{2.5}$ or, some other pollution 
indices to represent pollution. However, there are a few researches on the transmission mechanism about how the economic policy uncertainty influence environmental pollution. As the main body of economic activities and an important contributor to the pollution headstream, the role of enterprises' investment behavior in the transmission mechanism needs to be deeply analyzed. According to the existing theory and literature, we believe that economic policy uncertainty will destroy enterprises' forward expectation for the macroeconomy and maintain a prudent investment attitude to avoid losses. When the economic policy uncertainty is persistent, enterprises will reduce investment. Therefore, economic policy uncertainty will have an impact on pollution through investment channel.

At present, the popularization rate of global green energy is relatively low, and green energy is not very substitutable for traditional energy such as coal. Based on the research on the negative synergistic relationship between the economic policy uncertainty and $\mathrm{CO}_{2}$ emissions in the four countries, we propose the following two hypotheses.

Hypothesis 1. The investment effect of economic policy uncertainty on per capita $\mathrm{CO}_{2}$ emissions is smaller than consumption effect. This means that the higher the economic policy uncertainty index, the lower the per capita $\mathrm{CO}_{2}$ emissions.

Hypothesis 2. Compared with advanced countries, the higher the economic policy uncertainty in emerging market countries, the larger negative impact on per capita $\mathrm{CO}_{2}$ emissions.

The content of this study is divided into five main parts. The first part compares and summarizes representative literature on socio-economic factors affecting environmental pollution. Then, we put forward the research hypotheses of this study based on them. In the second part, we give the sample data description and statistical description and explain the construction of the empirical model. In the third part, we carry out the stationarity test and the cointegration analysis on the sample data, expound the model selection and parameter estimation, and analyze the empirical results. The fourth section presents the robustness tests. The fifth part concludes the whole paper.

\section{Research Design and Methods}

\subsection{Sample Selection and Data Acquisitions}

We investigated the impact of economic policy uncertainty on air pollution using per capita $\mathrm{CO}_{2}$ as the explained variable and the economic policy uncertainty index as the core explanatory variable. In order to investigate the heterogeneity of this impact between advanced and emerging market countries, we constructed a dataset including both developed and emerging market countries.

Due to the availability of national data for economic policy uncertainty indicators, we can only obtain data for 20 countries. Then, this paper divides all countries into two groups, one is emerging market countries, and the other is advanced countries, to analyze the heterogeneity of effects of macroeconomic uncertainty on $\mathrm{CO}_{2}$. Refer to Dedola et al. [39], Kalemli-Özcan [40], and Avdjiev et al. [41], we put Brazil, Chile, China, India, Mexico, and Russia as emerging market countries and put Canada, France, Germany, Ireland, Italy, Japan, the Netherlands, Spain, the United Kingdom, the United States, Sweden, Greece, South Korea, and Singapore as advanced countries.

As the data of the Russia, Greece, South Korea, Singapore, and Mexico do not meet the requirement of stationarity, we removed these five countries from the empirical test. Although there are only four emerging market countries in the list, India and Brazil are both BRICS countries with typical characteristics of emerging market countries. Therefore, they can meet the requirements of our comparative analysis of the impact of economic policy uncertainty on $\mathrm{CO}_{2}$ emissions between emerging market countries and advanced countries.

Eventually, we used the panel data of 15 countries including the United States and China, covering the period from 1997 to 2019 to test our research hypotheses. We used per capita $\mathrm{CO}_{2}$ emissions as a proxy variable to describe the degree of environmental pollution, 
adopt EPU (economic policy uncertainty) index to describe economic policy uncertainty, let per capita GDP describe economic development, and use net inflow of foreign direct investment to measure the level of foreign investment. The source of $\mathrm{CO}_{2}$ was the World Bank, and the source of EPU was policyuncertainty.com.

Table 1 shows the basic statistical results of two core variables in the model, namely, per capita $\mathrm{CO}_{2}$ emissions and economic policy uncertainty index. First, in terms of per capita $\mathrm{CO}_{2}$ emissions, the top three countries were the United States, Canada, and the Netherlands, with average values of $18.97,17.07$, and 10.37, respectively. The country with the lowest level of per capita $\mathrm{CO}_{2}$ emissions was India, with an index of 1.3. Second, from the perspective of the mean value of economic policy uncertainty index, the three highest countries were Britain, France, and Canada, with the mean values of 189.53, 163.62, and 150.92, respectively. The country with the lowest mean value of economic policy uncertainty index was Sweden, with the mean value of 92.88 .

Table 1. Descriptive statistics of core variables.

\begin{tabular}{|c|c|c|c|c|c|c|c|c|c|c|}
\hline \multirow{2}{*}{$\frac{\text { Var. }}{\text { Country }}$} & \multicolumn{5}{|c|}{$\mathrm{CO}_{2}$} & \multicolumn{5}{|c|}{ EPU } \\
\hline & Mean & Max & Min & Ske. & Kur. & Mean & Max & Min & Ske. & Kur. \\
\hline Canada & 17.07 & 18.71 & 15.41 & -0.01 & -1.64 & 150.92 & 333.36 & 53.37 & 0.81 & -0.05 \\
\hline France & 6.25 & 7.28 & 4.97 & -0.28 & -1.57 & 163.62 & 317.12 & 37.60 & 0.22 & -1.29 \\
\hline Germany & 10.35 & 11.44 & 8.40 & -0.68 & 0.18 & 131.20 & 231.44 & 79.23 & 0.61 & -0.61 \\
\hline Ireland & 9.93 & 12.39 & 7.60 & -0.07 & -1.78 & 113.65 & 193.72 & 59.38 & 0.23 & -1.21 \\
\hline Italy & 7.33 & 8.62 & 5.57 & -0.42 & -1.58 & 109.31 & 163.68 & 60.14 & -0.03 & -0.23 \\
\hline Japan & 9.70 & 10.25 & 8.72 & -0.90 & 0.23 & 109.88 & 185.57 & 65.82 & 0.67 & 1.11 \\
\hline The Netherlands & 10.37 & 11.19 & 9.06 & -0.43 & -1.09 & 95.97 & 142.87 & 48.72 & 0.12 & -0.95 \\
\hline Spain & 6.77 & 8.39 & 5.39 & 0.13 & -1.64 & 101.97 & 178.05 & 57.63 & 0.58 & 0.06 \\
\hline The United Kingdom & 8.17 & 9.75 & 5.48 & -0.54 & -1.30 & 189.53 & 542.77 & 47.84 & 1.20 & 0.53 \\
\hline The United States & 18.97 & 21.29 & 16.06 & -0.24 & -1.74 & 120.91 & 188.70 & 67.14 & -0.04 & -0.97 \\
\hline Sweden & 5.46 & 6.62 & 4.19 & -0.22 & -1.57 & 92.88 & 111.88 & 65.22 & -0.44 & -0.93 \\
\hline Brazil & 2.05 & 2.58 & 1.75 & 0.61 & -1.08 & 142.00 & 346.49 & 64.22 & 1.86 & 3.19 \\
\hline Chile & 4.11 & 4.65 & 3.39 & -0.23 & -1.37 & 110.10 & 170.54 & 61.02 & 0.12 & -1.04 \\
\hline China & 5.09 & 7.10 & 2.54 & -0.30 & -1.66 & 150.06 & 588.37 & 48.74 & 2.35 & 6.13 \\
\hline India & 1.30 & 1.92 & 0.86 & 0.39 & -1.40 & 94.65 & 185.46 & 49.48 & 0.89 & 0.07 \\
\hline
\end{tabular}

\subsection{Empirical Model}

This paper takes per capita $\mathrm{CO}_{2}$ emissions as the explained variable $\left(\mathrm{CO}_{2}\right)$ and the net inflow of foreign direct investment (NFDI), economic policy uncertainty index (EPU), and per capita GDP (GDP) as explanatory variables to study the impact of economic policy uncertainty on air pollution in 15 countries. In order to distinguish the difference of the impact of economic policy uncertainty index on per capita carbon emissions between emerging market countries and advanced countries. This paper uses a dummy variable reflecting the level of national development according to the level of economic development of each country, which is recorded as Deve. We mark the emerging market countries as 1 and the advanced countries as 0 , and add an interaction term to the model in which the level of national development and economic policy uncertainty index are multiplied. It is recorded as Deve * EPU, the model is constructed as the following Equation (1).

$$
C O_{2 i t}=\alpha_{i}+\beta_{0}+\beta_{1 i} * N F D I_{i t}+\beta_{2 i} * G D P_{i t}+\beta_{3 i} * E P U_{i t}+\beta_{4 i} D e v e_{i t} * E P U_{i t}+\mu_{i t}
$$

In light of the differences among different countries, we first construct the panel variable coefficient model and select the optimal model based on the model estimation results. In addition, we need to choose individual fixed effects or individual random effects when construct the model. The fixed effects model (FEM) is as Equation (2).

$$
C O_{2 i t}=\alpha_{i}+\beta_{0}+\beta_{1} * N F D I_{i t}+\beta_{2} * G D P_{i t}+\beta_{3} * E P U_{i t}+\beta_{4} D e v e_{i t} * E P U_{i t}+\mu_{i t}
$$

Although the intercept may be different among different research objects, the intercept of each research object will not change with the change of time. Regression coefficients 
(slopes) do not change with the change of the research object or period. The random effects model (ECM) is as followings.

$$
\begin{gathered}
C O_{2 i t}=\alpha_{i}+\beta_{0}+\beta_{1} * N F D I_{i t}+\beta_{2} * G D P_{i t}+\beta_{3} * E P U_{i t}+\beta_{4} D e v e_{i t} * E P U_{i t}+\mu_{i t} \\
\alpha_{i}=\alpha_{1}+\varepsilon_{\mathrm{i}}
\end{gathered}
$$

The null hypothesis behind the Hausmann test is that there is no significant difference in the estimators between the fixed effects model and the random effects model. This statistic proposed by Hausmann asymptotically obeys the $\chi^{2}$ distribution.

If the null hypothesis is rejected, the conclusion is that the random effects model is not appropriate, because the random effects may be related to one or more regressors. In this case, the fixed effects model is better than the random effects model.

\section{Empirical Results on the Impact of Economic Policy Uncertainty on $\mathrm{CO}_{2}$ Emissions}

\subsection{Stationarity Test and Cointegration Analysis}

We construct data sets of 15 countries to study the impact of economic policy uncertainty on air pollution. Before building the panel model, we first need to test the stationarity of the time series, and then carry out the cointegration analysis on the basis of the stationarity of the data. If there is a co-integration relationship among variables, we can build a panel model for the empirical test.

The results of the unit root test are given in Table 2. We find that three different unit root tests reject the null hypothesis of non-stationarity. Therefore, the first difference of per capita $\mathrm{CO}_{2}$ emissions $\left(\mathrm{CO}_{2}\right)$, the net inflow of foreign direct investment (NFDI), economic policy uncertainty index (EPU), and per capita GDP(GDP) is stationary.

Table 2. Unit root test for panel data.

\begin{tabular}{ccccc}
\hline Method & Statistic & Prob & Cross-Sections & Sample Size \\
\hline Levin, Lin, and Chu t & -26.1595 & 0.0000 & 60 & 1245 \\
ADF & 992.3160 & 0.0000 & 60 & 1245 \\
PP & 1074.8300 & 0.0000 & 60 & 1260 \\
\hline
\end{tabular}

After per capita $\mathrm{CO}_{2}$ emissions $\left(\mathrm{CO}_{2}\right)$, the net inflow of foreign direct investment (NFDI), economic policy uncertainty index (EPU), and per capita GDP (GDP) satisfies the first-order stationarity, we further test whether there is a co-integration relationship among these variables. Table 3 shows the cointegration analysis results of the panel data, and it can be seen that there is a significant co-integration relationship among variables. Therefore, we can build a panel model to analyze the relationship between EPU and $\mathrm{CO}_{2}$ emissions. In view of the fact that the first difference of each sequence is stationary, the first order difference sequence is used to construct the panel model, and the model is shown in Equation (5).

$\Delta C O_{2 i t}=\alpha_{i}+\beta_{0}+\beta_{1 i} * \Delta N F D I_{i t}+\beta_{2 i} * \Delta G D P_{i t}+\beta_{3 i} * \Delta E P U_{i t}+\beta_{4 i} D e v e_{i t} * \Delta E P U_{i t}+\mu_{i t}$

Table 3. Cointegration analysis of the panel data.

\begin{tabular}{ccccc}
\hline Hypothesized & \multicolumn{2}{c}{ Fisher Stat. } & \multicolumn{2}{c}{ Fisher Stat. } \\
\hline No. of CE(s) & (from Trace Test) & Prob. & (from Max-Eigen Test) & Prob. \\
\hline None & 206.6 & 0.0000 & 119.9 & 0.0000 \\
At most 1 & 114.8 & 0.0000 & 66.43 & 0.0001 \\
At most 2 & 78.4 & 0.0000 & 50.9 & 0.0100 \\
At most 3 & 89.07 & 0.0000 & 89.07 & 0.0000 \\
\hline
\end{tabular}




\subsection{Model Selection and Parameter Estimation}

Estimation results of the mixed panel data model are shown in Table 4. Comprehensively considering the impact of the net inflow of foreign direct investment (NFDI), economic policy uncertainty index (EPU) and per capita GDP (GDP) on $\mathrm{CO}_{2}$ emissions $\left(\mathrm{CO}_{2}\right)$ in the current and lagged periods, we find that per capita GDP (GDP) with a lag of 1 order, economic policy uncertainty index (EPU) with a lag of 1 order, and the net inflow of foreign direct investment (NFDI) with a lag of 3 orders have significant influence on per capita $\mathrm{CO}_{2}$ emissions $\left(\mathrm{CO}_{2}\right)$.

Table 4. Estimation results of the mixed panel data model.

\begin{tabular}{ccccc}
\hline Variable & Coefficient & Std. Error & t-Statistic & Prob. \\
\hline $\mathrm{C}$ & -0.0615 & 0.0197 & -3.1199 & 0.0020 \\
$\Delta \mathrm{GDP}(-1)$ & $-9.79 \times 10^{-4}$ & $5.14 \times 10^{-4}$ & -1.9058 & 0.0577 \\
$\Delta \mathrm{NFDI}(-3)$ & $4.91 \times 10^{-13}$ & $2.80 \times 10^{-13}$ & 1.7554 & 0.0803 \\
$\Delta \mathrm{EPU}(-1)$ & $-2.11 \times 10^{-5}$ & $6.27 \times 10^{-6}$ & -3.3581 & 0.0009 \\
Deve $(-1)^{*} \Delta \mathrm{EPU}(-1)$ & -0.0027 & 0.0012 & -2.2135 & 0.0277 \\
\hline
\end{tabular}

At the same time, according to Table 4, GDP increment with a lag of 1 order, EPU increment with a lag of 1 order and an interaction term Deve * EPU with a lag of 1 order have a negative impact on per capita $\mathrm{CO}_{2}$ emissions, while FDI increment with a lag of 3 orders have a positive impact on per capita $\mathrm{CO}_{2}$ emissions. After determining the lag order of explanatory variables, we build the model of cross-sectional fixed effects and cross-sectional random effects and carry out the Hausmann test. The results of Hausmann test are shown in Table 5. According to the Hausmann test $(p<0.10)$, we should build a model of cross-sectional fixed effects.

Table 5. Results of the Hausmann test.

\begin{tabular}{|c|c|c|c|c|}
\hline Test Summary & & Chi-Sq. Statistic & Chi-Sq. d.f. & Prob. \\
\hline $\begin{array}{l}\text { Cross-section } \\
\text { random }\end{array}$ & & 9.477018 & 4 & 0.0502 \\
\hline \multicolumn{5}{|c|}{ Cross-section random effects test comparisons } \\
\hline Variable & Fixed & Random & Var(Diff.) & Prob. \\
\hline$\Delta \mathrm{GDP}(-1)$ & $-1.08 \times 10^{-3}$ & $-1.04 \times 10^{-3}$ & 0.0000 & 0.4050 \\
\hline$\Delta \mathrm{NFDI}(-3)$ & 0.0000 & 0.0000 & 0.0000 & 0.0858 \\
\hline$\triangle E P U(-1)$ & $-1.90 \times 10^{-5}$ & $-2.00 \times 10^{-5}$ & 0.0000 & 0.3825 \\
\hline $\operatorname{Deve}(-1) * \triangle \mathrm{EPU}(-1)$ & -0.0023 & -0.0024 & 0.0000 & 0.3267 \\
\hline
\end{tabular}

\subsection{Empirical Results and Explanation}

After the Hausmann test and the choice of the lag order of explanatory variables, we finally choose to build a model of the cross-sectional fixed effects as Equation (6).

$$
\Delta C O_{2 i t}=\alpha_{i}+\beta_{0}+\beta_{1 i} * \Delta N F D I_{i t}(-3)+\beta_{2 i} * \Delta G D P_{i t}(-1)+\beta_{3 i} * \Delta E P U_{i t}(-1)+\beta_{4 i} D_{e v e} * \Delta E P U_{i t}(-1)+\mu_{i t}
$$

Table 6 shows the results of the model of fixed effects. Combined with regression Equation (1), we find that the increment of economic policy uncertainty index has a significant negative impact on per capita $\mathrm{CO}_{2}$ emissions, i.e., the higher the economic policy uncertainty, the lower the per capita $\mathrm{CO}_{2}$ emissions of each country. We add the net inflow of foreign direct investment (NFDI) and per capita GDP (GDP) into regression Equations (2) and (3), in turn, and regress them with the dependent variable CO2. According to Table 6, after controlling the effect of NFDI and GDP, the impact of economic policy uncertainty on per capita $\mathrm{CO}_{2}$ emissions is still significantly negative. In order to further verify whether the relationship between economic policy uncertainty index and per capita $\mathrm{CO}_{2}$ emissions 
is different between developing and advanced countries, we add an interaction term to the model in which economic policy uncertainty index and economic development level are multiplied. Regression Equation (4) in Table 6 shows that the negative impact of economic policy uncertainty index of emerging market countries on per capita $\mathrm{CO}_{2}$ emissions is nearly three times that of advanced countries.

Table 6. The model of cross-sectional fixed effects.

\begin{tabular}{ccccc}
\hline Variable & $\mathbf{( 1 )}$ & $\mathbf{( 2 )}$ & $\mathbf{( 3 )}$ & $\mathbf{( 4 )}$ \\
\hline C & $-0.065967^{* * *}$ & $-0.083441^{* * *}$ & $-0.064311^{* * *}$ & $-0.063485^{* * *}$ \\
$\Delta$ EPU(-1) & $-0.00143^{* * *}$ & $-0.001345^{* * *}$ & $-0.00148^{* * *}$ & $-0.001084^{* * *}$ \\
$\Delta$ NFDI(-3) & & $5.75 \times 10^{-13 * *}$ & $5.24 \times 10^{-13 * *}$ & $5.54 \times 10^{-13 * * *}$ \\
$\Delta$ GDP(-1) & & & $-1.97 \times 10^{-5 * * *}$ & $-1.93 \times 10^{-5 * * *}$ \\
DEVE* $\Delta$ EPU(-1) & & & $-0.002276^{* *}$ \\
\hline & & Fixed Effects (Cross) & & -0.0054 \\
Canada-C & -0.0319 & -0.0319 & -0.0115 & -0.0242 \\
France-C & -0.0558 & -0.0558 & -0.0570 & 0.0119 \\
Germany-C & 0.0278 & 0.0278 & 0.0189 & -0.0361 \\
Ireland-C & 0.0001 & 0.0001 & -0.0302 & -0.1306 \\
Italy-C & -0.1148 & -0.1148 & -0.1212 & -0.2148 \\
Japan-C & -0.1594 & -0.1594 & -0.1974 & -0.0116 \\
The Netherland-C & -0.0459 & -0.0459 & -0.0155 & 0.0909 \\
Spain-C & 0.0914 & 0.0914 & 0.1063 & 0.1083 \\
The United Kingdom-C & 0.0980 & 0.0980 & 0.1169 & 0.3241 \\
The United States-C & 0.3041 & 0.3041 & 0.3390 & 0.1150 \\
Sweden-C & 0.1128 & 0.1128 & 0.1331 & -0.0373 \\
Brazil-C & -0.0293 & -0.0293 & -0.0709 & -0.0475 \\
Chile-C & -0.0675 & -0.0675 & -0.0524 & -0.1308 \\
China-C & -0.0916 & -0.0916 & -0.1423 & -0.0118 \\
India-C & -0.0380 & -0.0380 & -0.0158 & \\
\hline$* p<0.1$ *** $p<0.05, * * * p<0.01$. & & & & \\
\hline
\end{tabular}

According to estimation results of the panel data regression model, the investment effect of economic policy uncertainty on per capita $\mathrm{CO}_{2}$ emissions in these 15 countries is smaller than the consumption effect. The higher the economic policy uncertainty index, the lower the per capita $\mathrm{CO}_{2}$ emissions. The coefficient of the interaction term is significant at the 0.05 level, which indicates that the consumption effect of the economic policy uncertainty index is much larger than the investment effect in emerging market countries, and the negative impact of economic policy uncertainty on per capita $\mathrm{CO}_{2}$ emissions in emerging market countries is larger than advanced countries. Both Hypothesis 1 and Hypothesis 2 are valid.

\section{Robustness Test}

In order to test the robustness of research conclusions, we replace the economic policy uncertainty index of each country with the global economic policy uncertainty index. Based on the global economic policy uncertainty index, this paper studies the impact of economic policy uncertainty on per capita $\mathrm{CO}_{2}$ emissions.

Table 7 shows the results of the Hausmann test of the panel model based on the global economic policy uncertainty index. It can be seen that the panel data set is suitable for establishing a model of cross-sectional fixed effects. Similar to the panel regression based on the economic policy uncertainty index of various countries, we control the impact of per capita GDP, the net inflow of foreign direct investment and the interaction term. The panel regression results are shown in Table 8. 
Table 7. Results of the Hausmann test-GEPU(Global Economic Policy Uncertainty).

\begin{tabular}{ccccc}
\hline Test Summary & & Chi-Sq. Statistic & Chi-Sq. d.f. & Prob. \\
\hline Cross-section random & \multicolumn{4}{c}{4.895219} \\
\hline \multicolumn{5}{c}{ Cross-section random effects test comparisons } \\
\hline Variable & Fixed & Random & Var(Diff.) & Prob. \\
$\Delta$ GDP(-1) & $-3.05 \times 10^{-3}$ & $-2.98 \times 10^{-3}$ & 0.0000 & 0.3212 \\
$\Delta$ NFDI $(-3)$ & 0.0000 & 0.0000 & 0.0000 & 0.0606 \\
$\Delta$ GEPU(-1) & $-1.80 \times 10^{-5}$ & $-1.80 \times 10^{-5}$ & 0.0000 & 0.4186 \\
DEVE $(-1) * \Delta$ GEPU(-1) & -0.0026 & -0.0028 & 0.0000 & 0.3174 \\
\hline
\end{tabular}

Table 8. The model of cross-sectional random effects-GEPU.

\begin{tabular}{|c|c|c|c|c|}
\hline Variables & (1) & (2) & (3) & (4) \\
\hline $\mathrm{C}$ & -0.04587 & -0.06044 * & -0.042579 & -0.042965 \\
\hline$\triangle \mathrm{GEPU}(-1)$ & $-0.00365^{* * *}$ & $-0.00371^{* * *}$ & $-0.003736^{* * *}$ & $-0.002984^{* * *}$ \\
\hline$\Delta \mathrm{NFDI}(-3)$ & & $5.85 \times 10^{-13 * *}$ & $5.34 \times 10^{-13 * *}$ & $5.24 \times 10^{-13 * *}$ \\
\hline$\Delta \mathrm{GDP}(-1)$ & & & $-1.88 \times 10^{-5 * * *}$ & $-1.84 \times 10^{-5 * * *}$ \\
\hline $\mathrm{DEVE}^{*} \triangle \mathrm{GEPU}(-1)$ & & & & $-0.002821 *$ \\
\hline \multicolumn{5}{|c|}{ Random Effects (Cross) } \\
\hline Canada-C & -0.0255 & -0.0140 & -0.0060 & -0.0105 \\
\hline France-C & -0.0330 & -0.0377 & -0.0122 & -0.0171 \\
\hline Germany-C & 0.0243 & 0.0192 & 0.0147 & 0.0107 \\
\hline Ireland-C & 0.0018 & -0.0198 & -0.0208 & -0.0251 \\
\hline Italy-C & -0.0872 & -0.0989 & -0.0956 & -0.1003 \\
\hline Japan-C & -0.1069 & -0.1418 & -0.1437 & -0.1486 \\
\hline The Netherland-C & -0.0270 & -0.0068 & -0.0024 & -0.0068 \\
\hline Spain-C & 0.0613 & 0.0778 & 0.0655 & 0.0619 \\
\hline The United Kingdom-C & 0.0698 & 0.0906 & 0.0812 & 0.0776 \\
\hline The United States-C & 0.1944 & 0.2344 & 0.2165 & 0.2139 \\
\hline Sweden-C & 0.0826 & 0.1024 & 0.0861 & 0.0827 \\
\hline Brazil-C & -0.0272 & -0.0603 & -0.0529 & -0.0418 \\
\hline Chile-C & -0.0457 & -0.0364 & -0.0350 & -0.0237 \\
\hline China-C & -0.0618 & -0.1028 & -0.0951 & -0.0842 \\
\hline India-C & -0.0198 & -0.0057 & -0.0002 & 0.0113 \\
\hline
\end{tabular}

${ }^{*} p<0.1,{ }^{* *} p<0.05,{ }^{* * *} p<0.01$.

According to Table 8, the increment of economic policy uncertainty index still has a significant negative impact on per capita $\mathrm{CO}_{2}$ emissions, that is, the higher the economic policy uncertainty, the lower the per capita $\mathrm{CO}_{2}$ emissions of each country. Similarly, we add the net inflow of foreign direct investment (NFDI) and per capita GDP (GDP) into regression Equations (2) and (3) in turn, and regress the dependent variable $\mathrm{CO}_{2}$. After controlling NFDI and GDP, the impact of economic policy uncertainty on per capita $\mathrm{CO}_{2}$ emissions is still significantly negative. Regression Equation (4) in Table 8 shows that the negative impact of economic policy uncertainty index of emerging market countries on per capita $\mathrm{CO}_{2}$ emissions is nearly twice that of advanced countries.

According to the results of robustness test, although the economic policy uncertainty index of each country is replaced by the global economic policy uncertainty index, economic policy uncertainty still has a significant negative impact on per capita $\mathrm{CO}_{2}$ emissions, and the negative impact of emerging market countries is significantly larger than advanced countries. The conclusion of this paper is still valid under strict robustness test.

\section{Discussion and Conclusions}

\subsection{Discussion}

There is no agreement in the existing literature on the relationship between economic policy uncertainty and air pollution. They investigate the effects of economic policy uncertainty on air pollution from different perspectives. Some literatures propose that there is a positive relationship between $\mathrm{CO}_{2}$ emissions and the economic policy uncertainty index (Wang et al. [24], Jiang et al. [25], Pirgaip and Dinçergök [31]). Especially Adams et al. [11] 
make a deep research on resource-rich but crisis-prone economies, and obtain that higher levels of economic policy uncertainty adversely affect environmental sustainability for countries with higher levels of geopolitical risks. The other literatures propose that there is a negative relationship between $\mathrm{CO}_{2}$ emissions and the economic policy uncertainty index like Danish et al. [30]. We speculate that the main reason for this controversy is that there are many socioeconomic factors which affect the relationship between economic policy uncertainty and air pollution, such as resources, and other related factors (Rehman [26], Degiannakis et al. [27], Antonakakis et al. [28], Bekiros et al. [29]). Scholars control for different economic variables depending on the study objectives, which lead to different results.

Besides that, the level of economic development is also an important influencing factor of the impact of economic policy uncertainty on environmental pollution (Barassi and Spagnolo [12], Grossman and Krueger [13], Brogaard et al. [32], Baker et al. [33]). However, existing literatures do not take into account whether there is heterogeneity between different groups of countries. Based on the existing literatures, we not only make research on the causal effect from economic policy uncertainty to pollution, but also investigate whether differences in the level of economic development affect the impact of economic policy uncertainty on air pollution between emerging market countries and advanced countries, trying to fill the research gap of existing literatures.

\subsection{Conclusions}

We take per capita $\mathrm{CO}_{2}$ emissions of each country as the explained variable, economic policy uncertainty index of each country as a core explanatory variable to construct a panel model to analyze the impact of economic policy uncertainty index on $\mathrm{CO}_{2}$ emissions. The sample period covers the period from 1997 to 2019. In order to highlight the heterogeneity of countries with different levels of economic development, we control per capita GDP, the net inflow of foreign direct investment, and the interaction term.

According to the empirical results, the overall impact of economic policy uncertainty index on $\mathrm{CO}_{2}$ emissions is significantly negative, which is consistent with Danish et al. [30]. In addition, we think that our study is also consistent with Adams et al. [11]. Controlling for resource stocks and probability of crisis, Adams et al. [11] suggest that economic policy uncertainty delays the commissioning and use of new energy sources, causing a lag in energy upgrading, which in turn increases $\mathrm{CO}_{2}$ emissions. Our study also suggests that the "investment effect" of economic policy increases $\mathrm{CO}_{2}$ emissions, but it is smaller than the "consumption effect," and the overall effect of economic policy uncertainty on $\mathrm{CO}_{2}$ emissions is negative. To some extent, our study is a further extension of Adams et al. [11]

The consumption effect of the economic policy uncertainty index on $\mathrm{CO}_{2}$ emissions is much larger than the investment effect, which is consistent with Wang et al. [24], and this difference is more prominent in emerging market countries. The negative impact of economic policy uncertainty index of emerging market countries on per capita $\mathrm{CO}_{2}$ emissions is nearly three times that of advanced countries. What's more, the conclusion is still valid when the economic policy uncertainty index of each country is replaced by the global economic policy uncertainty index.

Overall, the impact of current economic policy uncertainty on green energy and renewable energy investment is relatively limited. The main reason is that the development of new energy and green economy is still in the early stage. In the process of dealing with global warming and air pollution control, all countries in the world should speed up the upgrading of traditional energy industry, improve the substitutability for coal and other traditional energy, and work together for the sustainable development of the world economy.

This study examines the heterogeneity of the impact of the economic policy uncertainty on air pollution between advanced and emerging market countries, based on relevant literature. The classification of countries is based on the level of economic development. It does not go far enough into the level of development of the green economy and influence of geopolitics. Subsequent studies by scholars can further focus on the development of 
green economy, including the impact of the use of new energy on air pollution. After controlling the differences between investments in green economy and traditional investments, some more interesting conclusions may be drawn. However, it is worth mentioning that quantifying the level of green economy development is indeed a challenge. What's more the popularity of green energy has typical geopolitical characteristics, such as the higher level of green energy popularity in Europe. Analyzing the differences between "groups" of countries with the same geopolitical situation (i.e., G8-G20-EU-BRICS, etc.) is also a highly valuable research direction.

Author Contributions: This study is the result of teamwork. All authors equally contributed in designing the study, analyzing the data, writing the draft, and revising the study. Authors are ranked alphabetically by author's last name. All authors have read and agreed to the published version of the manuscript.

Funding: This research received no external funding.

Institutional Review Board Statement: Not applicable.

Informed Consent Statement: Not applicable.

Data Availability Statement: The study did not report any additional data.

Conflicts of Interest: The authors declare no conflict of interest.

\section{References}

1. Chang, Y.; He, Y.; Jin, X.; Li, T.; Shih, C.M. Media Coverage of Environmental Pollution and the Investment of Polluting Companies. Asia Pac. J. Financ. Stud. 2020, 49, 750-771. [CrossRef]

2. Zheng, S.; Kahn, M.E. A New Era of Pollution Progress in Urban China? J. Econ. Perspect. 2017, 31, 71-92. [CrossRef]

3. Dietz, S.; Fankhauser, S. Environmental Prices, Uncertainty and Learning. Oxf. Rev. Econ. Policy 2010, 26, 270-284. [CrossRef]

4. Bloom, N. The Impact of Uncertainty Shocks. Econometrica 2009, 77, 623-685. [CrossRef]

5. Acaravci, A.; Ozturk, I. On the relationship between energy consumption, $\mathrm{CO}_{2}$ emissions and economic growth in Europe. Energy 2010, 35, 5412-5420. [CrossRef]

6. Soytaş, U.; Sari, R. The relationship between energy and production: Evidence from Turkish manufacturing industry. Energy Econ. 2007, 29, 1151-1165. [CrossRef]

7. Bernanke, B.S. Irreversibility, Uncertainty, and Cyclical Investment. Q. J. Econ. 1983, 98, 85-106. [CrossRef]

8. Pindyck, R. Irreversible Investment, Capacity Choice, and the Value of the Firm. Am. Econ. Rev. 1988, 78, 969-985. [CrossRef]

9. Dixit, A. Entry and Exit Decisions under Uncertainty. J. Political Econ. 1989, 97, 620-638. [CrossRef]

10. Adedoyin, F.F.; Zakari, A. Energy consumption, economic expansion, and $\mathrm{CO}_{2}$ emission in the UK: The role of economic policy uncertainty. Sci. Total Environ. 2020, 738, 140014. [CrossRef]

11. Adams, S.; Adedoyin, F.; Olaniran, E.; Bekun, F.V. Energy consumption, economic policy uncertainty and carbon emissions; causality evidence from resource rich economies. Econ. Anal. Policy 2020,68, 179-190. [CrossRef]

12. Barassi, M.R.; Spagnolo, N. Linear and Non-linear Causality between $\mathrm{CO}_{2}$ Emissions and Economic Growth. Energy J. 2012, 33, 23-38. [CrossRef]

13. Grossman, G.M.; Krueger, A.B. Economic Growth and the Environment. Q. J. Econ. 1995, 110, 353-377. [CrossRef]

14. Ang, J.B. Economic development, pollutant emissions and energy consumption in Malaysia. J. Policy Model. 2008, 30, 271-278. [CrossRef]

15. Zhang, X.-P.; Cheng, X.-M. Energy consumption, carbon emissions, and economic growth in China. Ecol. Econ. 2009, 68, 2706-2712. [CrossRef]

16. Lean, H.H.; Smyth, R. CO $\mathrm{CO}_{2}$ emissions, electricity consumption and output in ASEAN. Appl. Energy 2010, 87, 1858-1864. [CrossRef]

17. Cai, Y.; Sam, C.Y.; Chang, T. Nexus between clean energy consumption, economic growth and $\mathrm{CO}_{2}$ emissions. J. Clean. Prod. 2018, 182, 1001-1011. [CrossRef]

18. Belloumi, M. Energy consumption and GDP in Tunisia: Cointegration and causality analysis. Energy Policy 2009, 37, 2745-2753. [CrossRef]

19. Fallahi, F. Causal relationship between energy consumption (EC) and GDP: A Markov-switching (MS) causality. Energy 2011, 36, 4165-4170. [CrossRef]

20. Farzin, Y.H.; Kort, P.M. Pollution Abatement Investment When Environmental Regulation Is Uncertain. J. Public Econ. Theory 2000, 2, 183-212. [CrossRef]

21. Pearce, D. Policy Forum: Designing a Carbon Price Policy: Empirical Uncertainties in Climate Policy Implementation. Aust. Econ. Rev. 2012, 45, 114-124. [CrossRef]

22. Jotzo, F.; Jordan, T.; Fabian, N. Policy Uncertainty about Australia's Carbon Price: Expert Survey Results and Implications for Investment. Aust. Econ. Rev. 2012, 45, 395-409. [CrossRef] 
23. Teeter, P.; Sandberg, J. Constraining or Enabling Green Capability Development? How Policy Uncertainty Affects Organizational Responses to Flexible Environmental Regulations. Br. J. Manag. 2016, 28, 649-665. [CrossRef]

24. Wang, Q.; Xiao, K.; Lu, Z. Does Economic Policy Uncertainty Affect $\mathrm{CO}_{2}$ Emissions? Empirical Evidence from the United States. Sustainability 2020, 12, 9108. [CrossRef]

25. Jiang, Y.; Zhou, Z.; Liu, C. Does Economic Policy Uncertainty Matter for Carbon Emission? Evidence from US Sector Level Lata. Environ. Sci. Pollut. Res. 2019, 26, 24380-24394. [CrossRef]

26. Rehman, M.U. Do oil shocks predict economic policy uncertainty? Phys. A Stat. Mech. Appl. 2018, 498, 123-136. [CrossRef]

27. Degiannakis, S.; Filis, G.; Panagiotakopoulou, S. Oil price shocks and uncertainty: How stable is their relationship over time? Econ. Model. 2018, 72, 42-53. [CrossRef]

28. Antonakakis, N.; Chatziantoniou, I.; Filis, G. Dynamic spillovers of oil price shocks and economic policy uncertainty. Energy Econ. 2014, 44, 433-447. [CrossRef]

29. Bekiros, S.; Gupta, R.; Paccagnini, A. Oil Price Forecastability and Economic Uncertainty. Econ. Lett. 2015, 132, 125-128. [CrossRef]

30. Ulucak, R.; Khan, S.U.G. Relationship between Energy Intensity and $\mathrm{CO}_{2}$ Emissions: Does Economic Policy Matter? Sustain. Dev. 2020, 28, 1457-1464.

31. Pirgaip, B.; Dinçergök, B. Economic policy uncertainty, energy consumption and carbon emissions in G7 countries: Evidence from a panel Granger causality analysis. Environ. Sci. Pollut. Res. 2020, 27, 30050-30066. [CrossRef] [PubMed]

32. Brogaard, J.; Detzel, A. The Asset-Pricing Implications of Government Economic Policy Uncertainty. Manag. Sci. 2015, 61, 3-18 [CrossRef]

33. Baker, S.R.; Bloom, N.; Davis, S.J. Measuring Economic Policy Uncertainty. Q. J. Econ. 2016, 131, 1593-1636. [CrossRef]

34. Coibion, O.; Georgarakos, D.; Gorodnichenko, Y.; Kenny, G.; Weber, M. The Effect of Macroeconomic Uncertainty on Household Spending. SSRN Electron. J. 2021. [CrossRef]

35. Gulen, H.; Ion, M. Policy Uncertainty and Corporate Investment. Rev. Financ. Stud. 2015, 29, 523-564. [CrossRef]

36. Stockhammar, P.; Österholm, P. The Impact of US Uncertainty Shocks on Small Open Economies. Open Econ. Rev. 2017, 28, 347-368. [CrossRef]

37. Aizenman, J.; Marion, N.P. Policy Uncertainty, Persistence and Growth. Rev. Int. Econ. 1993, 1, 145-163. [CrossRef]

38. Bloom, N.; Floetotto, M.; Jaimovich, N.; Eksten, I.S.; Terry, S. Really Uncertain Business Cycles. SSRN Electron. J. 2014, 86, 1031-1065. [CrossRef]

39. Dedola, L.; Rivolta, G.; Stracca, L. If the Fed sneezes, who catches a cold? J. Int. Econ. 2017, 108, S23-S41. [CrossRef]

40. Kalemli-Özcan, S. US Monetary Policy and International Risk Spillovers. In NBER Working Paper; National Bureau of Economic Research: Cambridge, MA, USA, 2019.

41. Avdjiev, S.; Hardy, B.; Kalemli-Ozcan, S.; Servén, L. Gross Capital Flows by Banks, Corporates and Sovereigns. In NBER Working Paper; National Bureau of Economic Research: Cambridge, MA, USA, 2019. 